\title{
International legal regulation of road transportation (features of the legal consciousness of legislators)
}

\author{
R.B. Bryukhov ${ }^{1}$ and K.E. Kovalenko ${ }^{2 *}$ \\ ${ }^{1}$ Ural State Law University, Yekaterinburg, Russia \\ ${ }^{2}$ Altai State University, Barnaul, Russia
}

\begin{abstract}
The contract of international carriage is a special type of foreign economic transactions. The specificity of this agreement is due to the peculiarities of transport as a natural monopoly of the state. The contract of international carriage includes public law (determination of the status of the transport environment) and private law (direct organization of the carriage itself) aspects. International carriage is the carriage of goods and passengers between two or more states in accordance with the terms of an international agreement concluded between them.
\end{abstract}

\section{Introduction}

International road transport is the carriage of goods and passengers by a motor vehicle on the basis of an international agreement in which the point of departure is located in the territory of one state, the destination point is in the territory of another, and also transit traffic. The agreement on the international carriage of goods by road is a special type of foreign trade transaction, a special commercial agreement: road haulage is usually not carried out by the parties to the contract, but by the associated companies that can themselves conclude a road haulage agreement. The most characteristic legal feature of these agreements is their nature as a double foreign trade transaction.

Multilateral agreements in the field of international road transport are adopted at the regional level. In Europe, there are: the Convention on Road Traffic (1949) (valid in terms of traffic management) and its Protocol on Road Signs and Signals (1949); Convention on Road Traffic (1968) (enshrines a uniform system of road signs and signals, a single road marking); 1971 European Agreement supplementing the Convention on Road Traffic (1968); Protocol on Road Signs and Signals (1968); European Agreement concerning the International Carriage of Dangerous Goods by Road (ADR) (1957); European Agreement on International Highways (AGR) (1975) (regulates the organization of the use of highways).

In addition, the system of international treaties in the field of road transport includes the following conventions:

\footnotetext{
* Corresponding author: publisher88@mail.ru
} 
- UNECE Geneva Convention on the Contract for the International Carriage of Goods by Road (1956) (CMR / DTM), as amended by the Geneva Protocol of 1978;

- The UNECE Geneva Convention on the contract for the international carriage of passengers and baggage by road (1973) (CAPP), as amended by the Geneva Protocol of 1978;

- UNECE Customs Convention on the International Transport of Goods under Cover of TIR Carnets (1975) (TIR / TJ Convention);

- The UNECE European Agreement concerning the work of crews of vehicles engaged in international road transport (1970) (as amended in 2004).

- Among European agreements, the main role is played by the Geneva Convention on the Contract for the International Carriage of Goods by Road (CMR / DEM) (1956) and the Geneva Customs Convention on the International Carriage of Goods using TTO Carnets (TIR Carnets) (1975) (TIR Convention).

\section{Methods}

The current research uses the methods of observation, comparative legal studies, formal logic, description, and interpretation. The transportation of passengers and baggage by road, in our opinion, should be defined as the movement of individuals with their belongings by means of vehicles not connected to the power grid, on wheels with their own engine on the roads or chartering a vehicle to transport a passenger and baggage. Determining the place of contract for the carriage of passengers and baggage by road in the system of obligations for transportation, it can be stated the following. The contract for the carriage of passengers and baggage by road represents an independent contract in the group of contracts for the carriage of passengers and baggage by vehicles. In this group, it is also possible to identify such types of contracts for the carriage of passengers and baggage, such as transportation by urban ground electric transport, rail, sea and river transport, air transport, tracked transport (Figure 1).

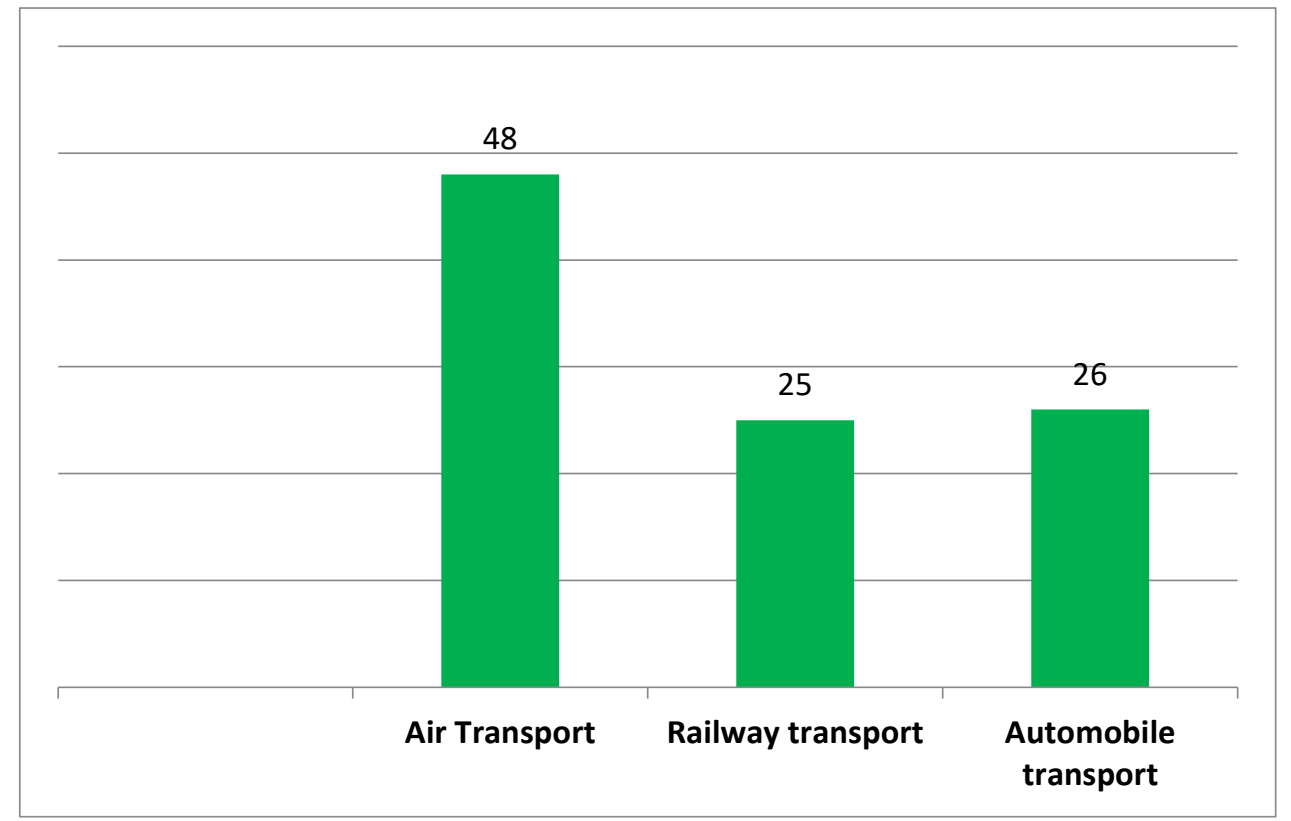

Fig. 1. Structure of passenger turnover, percent. 


\section{Discussion}

In the CMR, the conditions for the international carriage of goods by road were unified. The field of application of the CMR is the regulation of the relationship between the carrier and the cargo owner, the procedure for accepting cargo for transportation and issuing it at the place of destination. Scope of the CMR: all contracts for the carriage of goods by road for remuneration by means of vehicles (cars, cars with semi-trailers, trailers, and semitrailers) when the loading point and place of delivery are in two different states, at least one of which is a party to the Convention. CMR is also applied in cases where shipments are carried out by states or government agencies.

The CMR provides detailed rules for all basic conditions of carriage; a list of shipments to which the Convention does not apply (transportation of mail and dead; transportation of furniture when moving; the part of multimodal transport, which relates to water, air and rail transport without overload). The application of the Convention does not depend on the place of residence and nationality of the parties to the contract.

The norms of the CMR are imperative - derogations from its provisions are not valid; the parties do not have the right to change its rules in narrower agreements. CMR is a conglomerate of substantive and conflict of laws rules. Conflict regulation provides for the application of general and special conflict of laws rules: autonomy of will, law of the court, law of the place of departure and location of the cargo (general); the law of the location of the head office of the defendant's enterprise, the law of the location of the office that entered into the contract, the law of the place where the goods are presented to the carrier (special). The 1975 Geneva Customs Convention on the International Transport of Goods using T1I carnets (TIR Carnets) (TIR Convention) determines the procedure for completing customs formalities and the procedure for customs inspection during international road transport of goods. The main attribute of the Convention is the TIR Carnet (single customs document), the holder of which takes advantage of the priority customs clearance (TII sign). In the participating states, special guaranteeing institutions are in place to protect persons using the TIR procedure for the international carriage of goods by road. The TIR Convention establishes fairly stringent requirements for vehicles - their technical condition, environmental standards.

There are about 40 international organizations dealing with road transport. Among them, the most respected are the UNECE Inland Transport Committee (ITC) and the International Road Transport Union (IRU). ITC was established in 1948 as an intergovernmental body for the development of cooperation in the field of all types of inland transport. All UNECE member countries are members of the Committee.

The Inland Transport Committee has developed about 40 international conventions, more than 50 uniform regulations (rules) on the construction of vehicles. With the participation of ITC, a system of compulsory insurance of civil liability of vehicle owners for the damage caused was developed - the "green card" system.

The licensing system for the international carriage of goods is used to regulate the number of foreign trucks entering the country and protect the interests of national carriers. If transportation is carried out between countries that have not entered into bilateral agreements with each other, permits may be issued on a one-time basis by the competent authorities of the carrier's country. In the practice of European countries, there are several types of permits:

1) permission for one flight;

2) permission for multiple flights;

3) permission for a certain number of flights;

4) transit permits;

5) permits for suburban transportation. 
Russian permissions and permissions of countries with which bilateral agreements have been concluded refer, as a rule, to permits of the first type and are of a one-off character. Transportation to and from third countries is carried out on the basis of a "standard international license" issued with the permission of the European Conference of Ministers of Transport (ECMT). Since 1997, Russia is a member of the ECMT.

The international carriage of passengers and goods by vehicles is carried out under the condition of compulsory third party liability insurance of the carrier. Each carrier is obliged to insure in advance its civil liability for each vehicle. Insurance should cover all damage that may be caused by vehicles.

Russia participates in a large number of bilateral international treaties on international automobile communication. All these agreements contain general provisions - a licensing system for the international road transport of passengers, baggage and cargo is established, the issues of transportation to and from third countries are resolved (for example, the Russian-Austrian agreement on international road transport).

The legal status of the land transport environment is connected with the legal status of the state territory on which the transportation is carried out. It is based on the sovereignty of the state on the territorial entities belonging to it. At the same time, the legal regime of land carriage is subject to the norms of the international law on road traffic management (Convention on Road Traffic of September 19, 1949); customs clearance procedures (Geneva Customs Convention of 1975 on the International Carriage of Goods by TIR Carnet); motorway management (European Agreement, 1975 on international motorways). International road transport of goods is governed by the 1956 Geneva Convention on the Contract for the International Carriage of Goods by Road (CMR), which entered into force on July 2, 1961.

Let's consider the scope of application of the Convention on the Contract for the International Carriage of Goods by Road.

The Convention governs the relationship between the carrier and the cargo owner who have entered into a contract for the carriage of cargo, the procedure for receiving cargo for transportation and issuing it at the point of destination.

The Convention applies to any contract for the carriage of goods by road for remuneration by means of transport when the place of loading of cargo and place of delivery of cargo specified in the contract are in two different countries, at least one of which is a party to the Convention, and also if shipments are made by states or government agencies or organizations.

The convention does not apply:

- for carriage performed in accordance with international postal conventions;

- for the carriage of dead;

- for transportation of furniture when moving;

- for shipments between the United Kingdom of Great Britain and Northern Ireland and the Republic of Ireland;

- to that part of multimodal transport, which refers to the transport by sea, rail, inland waterway or air transport without overload.

European carriers are distinguished by high qualification of drivers (due to competitive selection and training). Against the background of the overall financial sustainability of the EU market operators and the operation of the newest rolling stock, they are characterized by their customers as the most reliable. Russian drivers, in addition to working at an average tariff of 0.9 euros per kilometer, spend $35-40 \%$ of the total cost on fuel. Besides, over the past four years, the cost of diesel fuel sold in Russia has increased by an average of 2.5 times, whereas in Germany only by $36 \%$, and in Finland by $11 \%$. But it was precisely due to the significant difference in the cost of fuel in Russia and Europe, taking into account the lack of restrictions on the import of fuel to Finland, domestic carriers managed 
to maintain an acceptable profitability. Currently, on a number of routes, profits are close to zero, and the process of rolling stock renewal has slowed down significantly. It is also very important that Russian carriers, in fact, did not have the opportunity to pay drivers a decent salary to market demand. Therefore, in recent years, there has been a shortage of qualified driving personnel.

\section{Basic conditions for international road transport}

International road transport of goods in European countries, including Russia and many CIS countries, is carried out on the basis of the provisions of the CMR concluded in Geneva in 1956 (entered into force for the USSR (assignee Russia) on December 1, 1983). In Latin writing, the convention sounds like a CMR.

This Convention applies to any contract for the international carriage of goods by road. When the place of loading of goods and the place of delivery specified in the contract are in the territory of two different countries, of which at least one of the parties is a party to the Convention.

If on a part of the route of transportation the vehicle is transported together with the cargo it carries by sea, rail, inland waterway or by air, this Convention applies to the entire journey as a whole.

Under the provisions of this Convention, the haulier is responsible both for his actions and omissions and for the actions and omissions of his agents and all other persons whose services he resorts to in order to carry the carriage.

The contract of carriage is established by the international consignment note, called in operational terms the CMR consignment note in Latin abbreviation of the name of the Convention itself. The form of the DEM consignment note is given in Appendix 18.

The consignor has the right to dispose of the goods, in particular, to require the carrier to stop the carriage, change the place provided for the delivery of the goods, or deliver the goods to the recipient who is indicated in the consignment note. The sender loses this right from the moment when the second copy of the invoice is transferred to the recipient.

The carrier is responsible for the total or partial loss of cargo or for its damage that occurred during the period between acceptance of the cargo for transportation and its delivery to the recipient. The carrier is relieved of this responsibility if he is not guilty or there were circumstances that the carrier could not avoid. The carrier may not refer to the defects of a motor vehicle in order to disclaim responsibility.

An authorized person may consider a shipment as lost if it has not been delivered within 30 days after the delivery date specified in the delivery note. If the deadline has not been determined, then within 60 days from the date of acceptance of the goods by the carrier. An authorized person may, upon receiving compensation for the lost cargo, request in writing that it should be returned immediately if the cargo is found within the year following the payment of compensation.

When the carrier is obliged to pay damages caused by full or partial loss of cargo, the amount to be reimbursed is determined on the basis of the value of the cargo and at the place and time of taking it for carriage. The value of the goods is determined on the basis of the exchange quotation, the current market price or the usual value of the goods of the same kind and quality.

In addition, transportation fees, taxes and charges, as well as other possible costs associated with transportation, are subject to reimbursement. The carrier is obliged to pay damages caused by delay in delivery if it is proved that the delay caused damage. In case of damage to the goods, the carrier pays the amount corresponding to the depreciation of the goods. If the recipient accepted the shipment and did not establish the condition of the shipment in the presence of the carrier, and subsequently notable losses or damages were 
identified, it is considered that the shipment was accepted by the recipient in the proper condition described in the consignment note.

Claims that may arise from shipments carried out in accordance with the Convention may be filed within one year. However, in the case of a malicious act or guilt, which, according to the law applied by the court which dismantles the case, is considered to be a malicious act, the period is set at three years.

The term is calculated:

- in case of partial loss of cargo, damage to it, or delay in delivery from the date of delivery;

- in case of loss of the entire cargo from the 30th day after the expiry of the deadline for carriage or, if it was not specified, from the 60th day upon acceptance of the cargo by the carrier;

- in all other cases upon the expiration of a three-month period from the date of the conclusion of the contract of carriage.

The filing of a complaint in writing suspends the period until the day when the carrier rejected the claim in writing with the return of the documents attached to it.

If the carriage, the terms of which are determined by a single contract, is carried out by several carriers, each of them is responsible for the entire carriage. The carrier accepting the goods from its predecessor hands over the last receipt dated and signed by him. He must mark the name and address on the second copy of the invoice.

\section{Conclusions}

In conclusion, large business actively uses the services of cargo transportation, both in the international arena and in the domestic market. Unlike business, private individuals use cargo transportation to solve local problems. As a rule, this is a residential or village moving, delivery of building materials, household items, etc. Transportation of private goods takes place over short distances within the city or region. Such transportation does not require heavy vehicles, and transport companies use light-duty vehicles. Combined transportation is often used on long-distance routes, when one vehicle transports cargo of different senders. Long-distance groupage cargo is most often carried out using the railway or heavy vehicles.

The freight market is constantly evolving. The process of cargo transportation is being improved by introducing new logistics technologies. Nearly for any cargo, there will be the most suitable type of transport in order to deliver the cargo to the destination at the lowest cost in the shortest possible time. The client only needs to choose the right transport company that will professionally perform the task of delivering the cargo.

\section{References}

1. URL: http://www.consultant.ru/cons/cgi/online.cgi?base $=L A W \& n=294690 \& d s t=$ 429496

7295\&cacheid $=6$ EAAB88D342A76CCFB97B0D5658E0426\&mode $=$ rubr\&req $=\mathrm{doc}$ \&rnd=DA3F551662AB8B78C228FDF1333E99EF\#07428796849859929.

2. URL: http://www.consultant.ru/cons/cgi/online.cgi?base $=\mathrm{LAW} \& \mathrm{n}=294690 \& \mathrm{dst}=$ 429496

7295\&cacheid $=6$ EAAB88D342A76CCFB97B0D5658E0426\& mode $=$ rubr\&req $=$ doc \&rnd=DA3F551662AB8B78C228FDF1333E99EF\#07428796849859929.

3. V.Vitryansky. Participants in contractual relations related to transportation. Economy and law, 2 (2010). 
4. V.V. Vitryansky. Contracts on the organization of cargo transportation. Economy and Right, 3 (2001)

5. G.S. Gurevich. On the issue of the legal nature of the contract of carriage of goods. Scientific notes, 67 (1964)

6. S.S. Alekseev. Civil liability for failure to fulfill the plan railway transportation of goods. (Moscow, 1959).

7. M.I. Braginsky, V.V. Vitryansky. Contract Law. Book 4: Treaties on transportation, towing, transport expedition and other services in the field of transport. (Moscow, 2004).

8. M.I. Braginsky, V.V. Vitriansky. Contract law. Book One: General Provisions. (Moscow, 2000)

9. Decree of the Government of the Russian Federation No. 766 of September 12, 2011 "On admission to operation of state aircraft". SZ RF, 38 (2011)

10. M.P. Bardina, B.A. Bulaevsky, N.G. Vilkova. Commentary on the Civil Code of the Russian Federation. (Moscow, 2010).

11. K.E. Kovalenko. World Applied Sciences Journal, 7 (2014)

12. A.M. Simonenko, O.N. Troitskaya. Commentary to the Air Code of the Russian Federation (article-by-article). (Moscow, 2007)

13. Order of the Ministry of Transport of the Russian Federation of 02.07.2007 № 85 "On Approval of the Rules for the State Registration of Civil Aircraft of the Russian Federation". Bulletin of Normative Acts of Federal Executive Bodies, 41 (2007)

14. N.V. Vartanyan. On the procedure for state registration of civil aircraft. Transport Law, 3 (2009)

15. I. Degtyarev. Without an application there is no transportation. Ezh-Lawyer, 32 (2001)

16. V.A. Egiazarov. Transport Law: A Textbook (Moscow, 2004)

17. Order of the Minister of Defense of the Russian Federation of 28.11.2002 No. 460 "On Approval of Federal Aviation Rules for State Registration of State Aircraft". Bulletin of Normative Acts of Federal Executive Bodies, 20 (2003).

18. Order of the Ministry of Transport of the Russian Federation No. 132 of May 16, 2003 "On Approval of Federal Aviation Regulations" A copy of an aircraft. Requirements and certification procedures ". Rossiyskaya Gazeta, 116 (2003)

19. V.D. Bordunov. International Air Law. (Moscow, 2007).

20. M.K. Aleksandrov-Dolnik. Disputes arising from the legal relationships of the parties in railway freight operations. (Moscow, 1955).

21. V. V. Vitryansky Contract of carriage. (Moscow, 2001). 